\title{
Linking high-risk preventive strategy to biomedical-industry market: implications for public health'
}

\section{Ligando a estratégia preventiva de alto-risco ao mercado da indústria biomédica: implicações para a saúde pública}

\author{
Armando Henrique Norman \\ Secretaria Municipal de Saúde do Rio de Janeiro. Rio de Janeiro, \\ RJ, Brasil. \\ E-mail: ahnormanळhotmail.com \\ David J. Hunter \\ Durham University. Durham, United Kingdom. \\ E-mail: d.j.hunterळdurham.ac.uk \\ Andrew J. Russell \\ Durham University. Durham, United Kingdom. \\ E-mail: a.j.russellळdurham.ac.uk
}

\begin{abstract}
This paper takes Geoffrey Rose's concepts on preventive strategy as the basis for theoretical framework to critically analyse the current approach to disease prevention. Rose's "continuum of risk and severity" has widened the scope for preventive actions and underpins two approaches: high-risk strategy (HRS) and population strategy (PS). Both of them produce paradoxes: HRS, despite having a good harm-benefit ratio, offers little impact on public health; PS has greater impact on public health, but offers minimal benefit at individual level. We argue that HRS is being misapplied by reducing cut-off points for preventive interventions to impact morbimortality attributed to specific diseases. This tends to medicalize prevention, producing more disease related phenomena through screening techniques, and inducing individual affective reactions, which require action in the present to secure better future health. This context has paved the way for speculative preventive medicine, which perceives health as a commodity but ignores its implications for public health services.

Keywords: Disease Prevention; Public Health; Quaternary Prevention; Medicalization; Commodification; Evidence-Based Medicine.
\end{abstract}

\section{Correspondence}

Armando Henrique Norman

Rua Evaristo da Veiga, 16, Cinelândia.

Rio de Janeiro, RJ, Brasil. CEP 20031-040.

1 The first author received financial support by Capes Foundation, process number 1032/12-7. 


\section{Resumo}

Este artigo aborda os conceitos de Geoffrey Rose sobre estratégia preventiva como base para análise teórico-crítica da abordagem atual para a prevenção de doenças. A proposta de Rose de um "continuum de risco e severidade" ampliou as possibilidades das ações preventivas ao classificar duas abordagens: a estratégia de alto risco (EAR) e a estratégia populacional (EP). Ambas produzem paradoxos: a EAR, apesar de apresentar boa relação dano-benefício, oferece pouco impacto para a saúde pública; a EP tem maior impacto sobre a saúde pública, mas oferece benefícios mínimos em nível individual. Argumentamos que a EAR tem sido mal utilizada ao reduzir pontos de corte para intervenções preventivas para impactar a morbimortalidade atribuída a doenças específicas. Isso tende a medicalizar a prevenção, produzindo mais fenômenos relacionados à doença por meio de técnicas de rastreamento, induzindo reações afetivas individuais que exigem ação no presente para garantir melhor saúde no futuro. Tal contexto abre caminho para a prática de uma medicina preventiva especulativa, que percebe a saúde como mercadoria, mas ignora suas implicações para os serviços de saúde pública.

Palavras-chave: Prevenção de Doenças; Saúde Pública; Prevenção Quaternária; Medicalização; Mercantilização; Medicina Baseada em Evidências.

\section{Introduction}

Evidence-Based Medicine (EBM) has been introduced as main paradigm for learning and practicing medicine in accordance to the best available scientific evidence in order to improve quality standards in clinical care (Harrison; Moran; Wood, 2002). In fact, EBM has been a watershed in medicine by improving overall quality and safety of patients' clinical care. Furthermore, if applied comprehensively, EBM could integrate "basic scientific principles, the subtleties of clinical judgment, and the patient's clinical and personal idiosyncrasies' (Greenhalgh; Howick; Maskrey, 2014). In addition, it has become policymakers' main instrument for assessing effectiveness of biomedical technologies and treatments. Nevertheless, according to Harrison (1998), EBM has also been used as a method for rationing healthcare's finite budget. Firstly, it frees politicians from difficult rationing decisions by seeming to offer a 'neutral' objective approach in decision-making processes on current and new biomedical technological innovations. Secondly, it provides the public with a scientific explanation about policymakers' rationing decisions. Thirdly, its hierarchical framework for assessing available medical knowledge has strengthened the medical authority (e.g. medical experts and researchers) while simultaneously reducing that of clinicians. Finally, it allows the production of clinical guidelines that doctors are obliged to adopt (Harrison; Moran; Wood, 2002). Thus, EBM can also be recognized as 'an indeterminate and malleable range of techniques and practices united not by particular kinds of methodological rigour, but by the pursuit of a new approach to medical knowledge and authority' (Lambert, 2006, p. 2639). In the UK context, this approach has led to the development of a robust clinical governance structure that paved the way for implementing the largest payfor-performance scheme in the world: the Quality and Outcomes Framework (QOF) (Norman; Russell; Merli, 2016).

Therefore, EBM is not value free and researchers' agendas have been tempered by pharmaceutical industries (Kelly et al., 2015). For example, randomized controlled trials (RCT), often regarded 
as the gold standard of evidence, create distortions arising from one or more of the following: manipulation of drug-dose response in both study arms (intervention and control); selectively enrolling patients most likely to respond to the intervention; adopting proxy outcomes; and failing to publish negative research findings, which can overestimate the benefits of intervention, thereby making it harder to replicate their outcomes in general population (Greenhalgh; Howick; Maskrey, 2014). As a result of this criticism, 'the EBM brand has been misappropriated and distorted by vested interests' (Greenhalgh; Howick; Maskrey, 2014, p. g3725). In particular, drug and medical devices industries increasingly set the research agenda. They define what counts as disease and pre-disease "risk states".

This context has fuelled the current debate on overdiagnosis and overtreatment, raising awareness and concerns about the role of preventive medicine. Overdiagnosis has been defined as diagnosis of conditions "that will never cause symptoms or death" often as a "consequence of the enthusiasm of early diagnosis". (Malhotra et al., 2015, p. h2308). These asymptomatic patients have been transformed into sick individuals and exposed to a range of psychological and physical side-effects without the prospect of benefit because they have been overtreated (Tesser; Norman, 2016). Thus, an increased body of evidence shows that some current preventive medicine activities may either lead to harm or suggest uncertainties surrounding its benefits (Welch; Fisher, 2017). Although prevention is portrayed as better than cure, the trend is to exaggerate certainty instead of taking a more balanced and honest approach to scientific findings and their limitations (Rose, 1992).

This article elaborates on Geoffrey Rose's (1992) seminal book, The Strategy of Preventive Medicine. We frame the discussion in six sections. The first one revisits the definition of disease as a 'quantifiable entity'. Section two presents Rose's approach to prevention: high-risk strategy (HRS) and population strategy (PS). Section three addresses their embedded paradoxes. In section four, we contend that the trends in prevention have centred on the misapplication of HRS by gradually reducing cut-off points for preventive interventions as means for addressing major disease outcomes. Based on two examples from an ethnographic study (Norman; Russell; Merli, 2016) of the QOF scheme, our final section highlights the advantage of prioritising HRS over PS to pharmaceutical industries. We argue that HRS has become mainstream in prevention because it fits a neoliberal economic approach to viewing health as a commodity.

\section{Continuum of risk and severity}

The fundamental misunderstanding of Rose's concept of preventive medicine refers to the continuum of risk and severity. This has helped blur the division between normal and pathological (Tesser; Norman, 2016). For Rose, the diagnostic criteria with their nosological entities (i.e. the international classification of diseases) are constructs for decision-making processes which doctors traditionally framed as disease diagnosis (Rose, 1992). The diagnostic process is, in fact, a tool that helps doctors decide whether or not to intervene upon the human body, i.e. it sets a clear cut-off point for intervention. It falls to professional judgement to decide whether a phenomenon is pathological and, if so, if the pathology warrants an intervention.

Rose challenged the limitations of such binary thinking and suggested that clinicians should think beyond pathological/non-pathological dualism, recognising the uncertain character of physiological processes. Hence, doctors should not just be concerned about whether a patient has, or does not have, a disease such as dementia, but how much of a disease a person has. Dementia, for example, may present across a whole spectrum of severity in the population from asymptomatic, oligo-symptomatic to frankly manifested. The consequences of this line of thought resulted in redefining disease as a 'quantifiable entity'. The quantification of disease allowed the expansion of medical interventions to individuals within the population who would previously have been regarded as healthy, since potentially everyone has a 'touch of disease' (Rose, 1992). 


\section{High-risk strategy and population strategy}

Rose's work demonstrates that the normal/pathological divide offers little benefit for population as a whole. Moving towards a continuum of risk and severity construct, he conceptualised two possible preventive medicine strategies: High-Risk Strategy (HRS) and Population Strategy (PS). HRS aims to separate a problematic minority (or the pathological ones) to be targeted through preventive measures from the rest of the population considered 'normal'. For instance, patients with underlying Coronary Heart Disease (CHD), such as angina, have a high-risk cardiovascular profile and should receive statins to reduce the likelihood of cardiovascular mortality. In contrast, PS aims to influence or to reduce the risk in population as a whole through public health initiatives. The anti-smoking campaign constitutes a good example of PS, where a raft of policy measures such as raising public awareness, higher taxation, banning smoking in public places and, more recently, in cars have had a major impact on tobacco consumption, contributing to a marked reduction in tobacco related diseases (Pell et al., 2008).

HRS and PS were seen as complementary strategies, but with the latter being more radical and effective than the former. Rose saw the population as an organic whole with changes in its entire distribution being more effective in reducing the overall burden of disease than targeting individual diseases. The PS approach aims to restore or facilitate biological homeostasis by creating a safer environment through removal of potential sources of ill-health. Therefore, changing social context into a healthier, fairer and less unequal environment has greater impact on human health (Wilkinson; Pickett, 2010). Figure 1 shows the left movement of whole risk factor distribution in a given population. PS is a powerful preventive intervention as it affects not only the high-risk, but also moderate to low risk individuals in the population.

\section{Figure I - Population strategy as powerful preventive option}

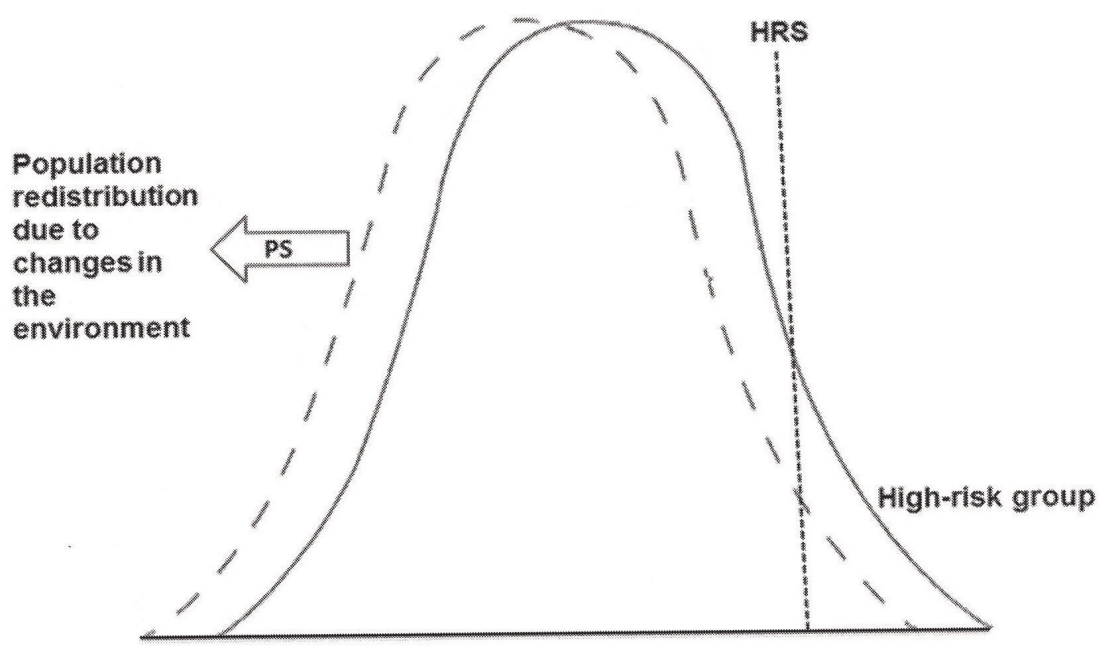

\section{Rose's preventive medicine paradox}

Preventive medicine strategy is characterised by Rose as a double-edged sword and gives rise to the preventive paradox both for HRS and PS. The paradox of PS is described as 'a preventive measure that brings large benefits to the community offers little to each individual participant' (Rose, 1992, p. 12), since each participant possesses low susceptibility to disease. For instance, in the case of restriction of salt content in processed foods, most of low to moderate risk profile individuals will be exposed 
to this intervention, although individually they are unlikely to benefit from it.

Nevertheless, HRS offers globally little impact on the population since high-risk groups represent a relatively small section of society. Thus, the second paradox: "the large number of people at a small risk may give rise to more cases of disease than the small number who are at a high-risk' (Rose, 2001, p. 431). Rose illustrates this paradox with the case of Down's syndrome: 40-years-old or older women carry much greater risk profile for having a baby with Down's syndrome, but they contribute only $13 \%$ to the total burden of the disease. Women who are low risk (below 30 years of age) produce half of the cases of Down syndrome because they form by far the greatest proportion of live births in the population (Rose, 2001).

However, the HRS concept is easily accommodated in medicine because it makes sense to both patients and health professionals. Its selective character discourages interference with those considered as 'normal' resulting in positive harm-tobenefit ratio and improved cost-effectiveness (Rose, 1992). These factors have contributed to the spread of HRS across primary care services.

\section{Solving the paradox: reducing the cut-off points for biomedical interventions}

The low impact of HRS on population health should have limited its utility as main preventive strategy, but 'experts' in public health have solved the paradox to which it gives rise by gradually lowering the threshold for intervention in healthy people. Figure 2 shows the reduction of a cut-off point for defining a preventive intervention. This transforms numerous asymptomatic people into sick, requiring more medical interventions and follow-ups. Thus, HRS leads inevitably to overdiagnosis and overtreatment as most individuals will not benefit from medical interventions.

The overemphasis on HRS has the effect of embracing more and more moderate to low-risk patients, backed by statistical figures, which boost the magnitude of the intervention, but distort the original ethos of public health (Starfield et al.,
2008). The understanding of diseases as quantifiable entities has facilitated researchers to gradually transform risk factors into diseases (Tesser; Norman, 2016) but more importantly, have allowed them mathematically reduce the cut-off threshold for interventions based on relative risk reduction in RCT. This can convey the notion of 'maximising benefit' for a given intervention despite low baseline susceptibility. Table 1 shows that the use of Relative Risk Reduction (RRR) numbers overestimates the benefit since it continues unchanged (20\%) despite the decrease in baseline mortality risk or susceptibility (Rembold, 1998). This increases the Number Needed to Treat (NNT) which is anchored in absolute risk reduction, i.e. the baseline susceptibility.

The expansion of HRS to impact overall population outcomes for a specific condition (e.g. statins for reducing cardiovascular mortality) predictably includes more healthy people with moderate to low-risk profiles. Thus, the harm-benefit pendulum inevitably swings towards the harm end outcome spectrum by spreading fear in the population and taking away people's sense of self-security (Heath, 2011).

Rather than applying population measures to address macro determinants of health, which can have a powerful impact on specific disease morbidity and mortality indicators, the default position in health promotion has been to individualise and capitalize on prevention. This phenomenon has been termed 'lifestyle drift', namely, 'the tendency for policy to start off recognising the need for action on upstream social determinants of health inequalities only to drift downstream to focus largely on individual lifestyle factors' (Popay; Whitehead; Hunter, 2010, p. 148).

'Lifestyle drift' reverses the PS approach, thus causing harm to many healthy people in the name of a better future population health. In other words, public health experts are aiming for population effect through targeting the individual, instead of acting principally at a 'whole of society' and 'wholeof-government' level to impact on the major determinants of health (WHO, 2013). This tension in policy arising from the corrosive effects of neoliberalism, and its contribution to widening health inequalities and poorer health in society, manifests itself in the emphasis on individual behavioural change in preference to tackling social determinants of health. 


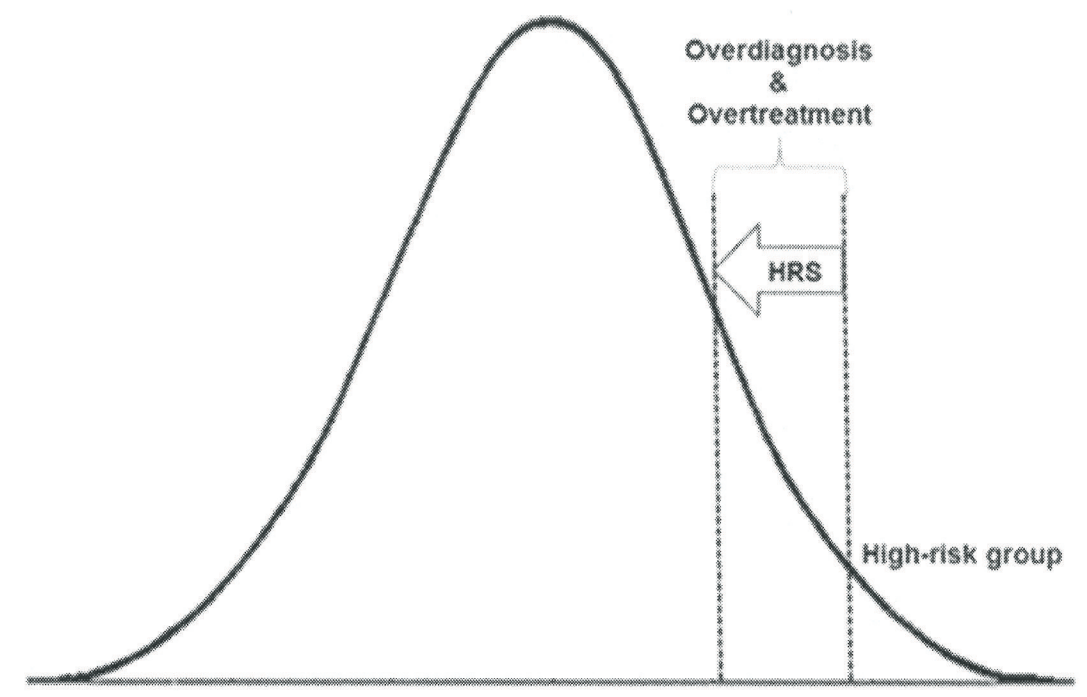

Table I - Relative Risk Reduction: a powerful number for conveying benefit

\begin{tabular}{lllll}
\multicolumn{2}{c}{ Mortality Risk } & \multicolumn{3}{l}{ Risk reduction } \\
$\begin{array}{l}\text { Control } \\
(\%)\end{array}$ & $\begin{array}{l}\text { Treatment } \\
(\%)\end{array}$ & $\begin{array}{l}\text { Relative } \\
(\%)\end{array}$ & $\begin{array}{l}\text { Absolute } \\
(\%)\end{array}$ & NNT $^{*}$ \\
\hline 5 & 4 & 20 & 1 & 100 \\
0.5 & 0.4 & 20 & 0.1 & 1,000 \\
0.05 & 0.04 & 20 & 0.01 & 10,000 \\
\hline
\end{tabular}

Source: Rembold, 1998

*NNT Number Needed to Treat.

Policies designed to reduce income disparities and confront vested interests of the global corporate sector, whose activities contribute to high levels of obesity, alcohol misuse and other lifestyle related conditions, through tougher regulation and taxation, are neglected in favour of those which leave these structural and commercial interests essentially untouched. Although public health built its reputation on the willingness of many of its key figures, like Rudolf Virchow, to challenge the prevailing political consensus and power imbalance in society, it has in more recent times been reluctant to engage with the political determinants of inequalities in income, power and resources (Collins; McCartney;
Garnham, 2016). The policy solutions offered are therefore failing to target those actors and actions responsible for the health gap and widening social gradient in health (Marmot, 2015).

\section{Reducing cut-off points in timeframe: bringing future into present}

HRS as a preventive approach pushes health staff to apply 'simulations or probabilistic anticipations' about patients' future health condition based on accumulated past statistical and epidemiological data (Adams; Murphy; Clarke, 2009). These data underpin a range of devices for calculating standardised individuals' disease risk profile, which requires interventions in the present in order to improve their future health profile. Thus, temporal dimension of care is transformed to produce an objectivity that claims truth about patients' fate (Adams; Murphy; Clarke, 2009). This sort of speculative preventive medicine "must inevitably decontextualize and efface the reality of everyday life and experience' (Lock; Nguyen, 2010, p. 26), but its figures are rarely discussed. 
All numbers addressed in prevention are anchored in population rather than individual level. Therefore, health professionals should make this clear to their patients by asserting that they aim to achieve an effect at population level (at least, this is the hope of policymakers). The 'success' of the intervention depends much more on capitation and compliance of patients with similar risk levels rather than the treatment of an individual isolated case. By adopting HRS as a population intervention, it produces uncertainty about who individually will benefit from it. For any particular person, treatment means that he/she must enrol in what is effectively an unbranded 'clinical trial' in order to achieve the desired population benefit through a sum of individualised interventions. The patients are pooled in a sea of uncertainty, which is seldom discussed in depth with them.

Usually, clinicians have difficulties in predicting the effect of a preventive intervention for an individual, since population studies have anonymised the asymptomatic person in front of them. This anonymity cannot be easily overcome by taking a patient-centred approach - even using information techniques for conveying probability. Additionally, clinicians' misinterpretation of statistics (e.g. use of relative risks instead of absolute risk), and, in some cases, not balancing against potential harms can convey unrealistic benefits of an intervention (Malhotra et al., 2015). For instance, clinicians often tend to speak to their patients in terms of 'Mr "X" your chances are...', but forget that EBM operates at very abstract mathematical realm of population-based study trials which know nothing about Mr "X", making it quite impossible in the case of preventive measure to transfer results to that person in particular. Thus, over time clinicians have undergone an acculturation process through training programmes, whereby this predictive reasoning has become normalised as best practice backed by, and incentivised to conform to pay-for-performance schemes, within which QOF stands as an example (Malhotra et al., 2015; Norman; Russell; Merli, 2016).

This predictive reasoning manifests itself through templates employed to inform individuals of their future cardiovascular outcomes, like the QRISK $2{ }^{\circledR}$ template, which automatically predicts individuals' risk. For instance, a 20\% risk prediction implies that over ten years in a cohort of 'same cases', 20\% will have a major cardiovascular event such as Myocardial Infarction (MI) or death due to cardiovascular disease. Mathematically, patients have an $80 \%$ chance of not having had an event in 10 years' time. This means that most people will be alive helping to build a background against which the benefits will abound since doctors cannot see the population effects by treating individual cases. This scenario tends to overestimate the benefit.

Moreover, if taking statins offers a possibility of, say, a $40 \%$ reduction in cardiovascular disease at the population level, this infers that $60 \%$ of those taking statins will still develop Coronary Heart Disease (CHD) major events. Finally, amongst individuals participating in this preemptive measure, the protective increment to the baseline is insignificant: before intervention the chances of not having a CHD event was $80 \%$ but after adhering to statins for ten years the chances of not having an adverse effect due to CHD has only increased to $88 \%$. It is undeniable that $8 \%$ reduction at a population level would represent a big achievement, but the means used for reaching these figures need to be reassessed. To quote Heath (2010, p. 93): 'however, worthy the end, turning humanity into simply the means to achieve it is to undermine what it is to be human in a very fundamental way'. Rose's concept that population intervention offers little for each individual participant is reinforced and becomes even clearer once this is done through an HRS approach, no matter how much experts play with the numbers to ensure statistically significant results (Abramson et al., 2013).

\section{High-risk strategy: advantage for the pharmaceutical industry}

The current preventive strategy adopts 'technological fix' in the hope of giving individual protection despite the adverse socioeconomic context. Rose (1992, p. 48) has pointed out important weaknesses of HRS: 'prevention becomes medicalized'; 'success is only palliative and temporary' which means that it needs constant maintenance of services by not addressing the diseases' root cause (i.e. 
socioeconomic health determinants); 'it is limited by poor ability to predict the future of individuals'. In other words, HRS creates uncertainties for the individuals receiving preventive intervention since patients are pooled in a risk-benefit population intervention (discussed further below). Although Rose warned of the weakness of HRS, for pharmaceutical industries its weakness has become their strength.

\section{Prevention becomes medicalized}

The adoption of HRS fosters medicalization of preventive activities. This is 'music to the ears' of drug companies. What has been witnessed during the last forty years is a tendency to resignify the usage of existing drugs by reducing cut-off points for prescribing them and hence labelling more people as sick (Lenzer, 2013), as well as by establishing hardto-reach targets for cholesterol, diabetes (HbiAc), blood pressure, obesity and the like (Montori; Isley; Guyatt, 2007). This approach has been systematically applied with the introduction of QOF.

The QOF as a pay-for-performance scheme consists of a point-based system that rewards UK general practice for achieving certain standards on pre-agreed clinical disease criteria. The aim has been to improve the quality of clinical care in general practice by setting an evidence-based clinical governance framework. The QOF 2013/2014 contract year offered 900 points and was organised into four domains: Clinical, Public Health, Quality and Productivity, and Patient Experience (Norman; Russell; Merli, 2016).
In some QOF clinical indicators policymakers have manipulated cut-off points for intervention and/or the range of points achievement of target-disease as mean of optimising treatment (Doran et al., 2014). In the QOF 2013/2014 contract this strategy was clearly used in regard to hypertension: QOF has tightened the hypertension target by placing fifty points (i.e. more money) to a 'newly' introduced QOF hypertension indicator $\mathrm{HYPoO}_{3}$ (requiring the blood pressure to be below 140/90) against ten points for HYPoo2 (requiring blood pressure to be below 150/90 - Table 2). This led to the inclusion of more patients under a tight blood pressure control.

By incentivizing reduced cut-off points, the QOF significantly increases the number of target people needing medical intervention, since it works at the population level or practices' catchment area. This process increases the number of laboratory tests, follow ups, and drugs being prescribed to reach a lower blood pressure threshold target within a cohort of hypertensive patients.

The QOF indicators for diabetes are another example of how policymakers have played with cutoff points and the upper-end threshold of a disease management quality standard. One of the criteria for a good diabetes control is through monitoring the level of haemoglobin A1c (HbA1c). Table 3 illustrates the fluctuation in $\mathrm{HbA1c}$ targeting and the increase in quality standards by expanding the upper range for maximum points. This leads to more patients on tighter diabetes control regimens and increase in medication usage.

\section{Table 2 - QOF hypertension indicator targets, points and range of achievement, 2013/2014}

Hypertension (HYP) indicators

Records

HYPooI. The contractor establishes and maintains a register of patients with established hypertension.

Ongoing Management

HYPoo2. The percentage of patients with hypertension in whom the last blood pressure reading (measured in the preceding nine months) is $150 / 90 \mathrm{mmHg}$ or less.

HYPoo3. The percentage of patients aged 79 or under with hypertension in whom the last blood pressure reading (measured in the preceding nine months) is $140 / 90 \mathrm{mmHg}$ or less (NICE $2012 \mathrm{menu}$ ID: NM53).

Achievement

thresholds

6

10

50

$$
44-84 \%
$$

0

$40-80 \%$

$40-80 \%$

Source: United Kingdom, 2013. 
Table 3 - Diabetes level of HbAIC in the previous fifteen months* organised by points' allocation ( $P$ ), range of achievement ( $R$ ), and QOF contract year

\begin{tabular}{|c|c|c|c|c|c|c|c|c|c|c|}
\hline \multirow{2}{*}{$\begin{array}{l}\text { QOF year } \\
\text { HbAic target } \\
\mathrm{mmol} / \mathrm{mol}(\%)\end{array}$} & \multicolumn{2}{|c|}{$2004 / 2005$} & \multicolumn{2}{|c|}{$2006 / 2007$} & \multicolumn{2}{|c|}{$2009 / 2010$} & \multicolumn{2}{|c|}{$2011 / 2012$} & \multicolumn{2}{|c|}{$2013 / 2014$} \\
\hline & $P$ & $\mathrm{R}(\%)$ & $\mathrm{P}$ & $\mathrm{R}(\%)$ & $\mathrm{P}$ & $\mathrm{R}(\%)$ & $\mathrm{P}$ & $\mathrm{R}(\%)$ & $\mathrm{P}$ & $\mathrm{R}(\%)$ \\
\hline $53 /(7.0)$ & & & & & 17 & $40-50$ & & & & \\
\hline $59 /(7.5)$ & 16 & $25-50$ & 17 & $40-50$ & - & - & 17 & $40-50$ & 17 & $35-75$ \\
\hline $64 /(8.0)$ & - & - & - & - & 8 & $40-70$ & 8 & $40-70$ & 8 & $43-83$ \\
\hline $75 /(9.0)$ & - & - & - & - & 10 & $40-90$ & 10 & $40-90$ & 10 & $52-92$ \\
\hline $86 /(10.0)$ & 11 & $25-85$ & $\|$ & $40-90$ & - & & & & & \\
\hline
\end{tabular}

Table 3 shows that in 2009/2010 QOF introduced three tiers for $\mathrm{HbAic}$ levels, placing more points on lower cut-off points $(53 / 7.0 \%=17$ points) inducing practitioners to be more aggressive in treating their diabetic patients. In 2013/2014 QOF contract year expanded the upper limits in all three tiers. Once more policy-makers have allocated more QOF points to lower bands of HbA1c: 17 QOF points to HbA1c $59 \mathrm{mmol} / \mathrm{mol}$ and eight QOF points to HbA1c $64 \mathrm{mmol} / \mathrm{mol}$. This meant that most diabetic patients had their levels of HbA1c geared towards the bottom end of $\mathrm{HbA1c}$ range, potentially increasing the use of medication and side effects (e.g. hypoglycaemia with hospitalisation). Nonetheless, the benefit of such intervention remains controversial as diabetes tight control (HbA1c below 6\%) increases patients' mortality rate (Currie et al., 2010). Ironically, during the last decade, the UK has experienced a $60 \%$ rise in diabetes cases, accounting for ' $10 \%$ of the NHS drugs bill' as 'nearly £869m was spent on drugs, including insulin and metformin, marking a sharp rise from the $£ 514 \mathrm{~m}$ being spent a decade ago' (Gallagher, 2015).

The adoption of HRS inevitably increases the consumption of biotechnologies and drugs (expanding the use of existing drugs which do not require further research cost for the pharmaceutical industry), but simultaneously drains public health resources. Most QOF domains focus on individualised preventive actions via consumption of biotechnologies and drugs. Polypharmacy has become the norm since the introduction of QOF: from 2004 to 2011 'prescriptions for statins doubled, for angiotensin converting enzyme inhibitors (for blood pressure control) and diabetic drugs nearly doubled, for antidepressants rose $60 \%$, and for steroid inhalers rose 30\%' (Spence, 2013, p. f1498). Despite this increase in medication usage, cardiovascular mortality has not diminished during the QOF's ten years of existence (Kontopantelis et al., 2015).

\section{Success is only palliative and temporary}

HRS is considered a palliative rather than a radical strategy as it does not address the underlining problems of disease causation. Thus, when implemented it requires constant maintenance. Looked at closely, HRS implies screening the population, which is a sieving process whereby asymptomatic people will be classified and targeted for preventive intervention. This process inevitably produces a snowball effect by generating new entities: positive results, pseudo-positive results (the source of overdiagnosis), false-positives, false-negatives, and borderline diseases (e.g. glucose intolerance, subclinical hyperthyroidism, cervical intraepithelial neoplasia [CIN, 1,2,3] etc.) multiplying health activities (and consequently the costs) in the name of optimising health (Raffle; Gray, 2007). This again creates a market reserve to be exploited by the biotechno-industrial complex operating upon a landscape made up of the collective human body. The strategy of this industrial complex may involve increasing patients' awareness about disease-related 
risks and specific preventive measures to be consumed, as well as by improving doctor-patient effective 'therapeutic' alliances through powerful discourses of EBM (Lambert, 2006) distilled into a set of financially incentivized scientific-bureaucratic rules (Harrison; Moran; Wood, 2002) embedded in pay-for-performance schemes to which clinicians have to conform (Norman; Russell; Merli, 2016).

\section{Poor ability to predict individuals' future}

HRS lacks predictive power upon individuals' future health. The current preventive medical model derives from individuals' uncertainty about the benefit of medical interventions. Based on large population studies or their meta-analyses, the model assumes that what holds for the sample (population trial) also holds for the whole population (inductive probabilistic/empiricist reasoning) just because individuals carry some biometrical resemblance (Harrison, 1998; Whitehead, 1967). This reinforces the concept of a socioeconomic decontextualized, collective and universal body that can be standardised for biomedical interventions (Lock; Nguyen, 2010). However, individual patients (and their doctors alike) tend to have a realist, deterministic reasoning tradition (Harrison, 1998) because they experience in their bodies the interventions and effects of medical practice.

The probabilistic reason based on empirical studies generates fetishized numerical concepts such as the NNT: the number of people needed to receive the intervention, during a certain period of time (five or ten years) to prevent one event (e.g. mortality due to myocardial infarction). Suppose that the NNT is 10o, meaning that 100 people should be treated during ten years to prevent one MI. From the patient's perspective, he/she believes they are the chosen one amongst 10o, because each of them experiences the effects of preemptive medical treatment (deterministic/realistic reasoning). This context of indeterminacy helps create the paradox of popularity: 'the greater overdiagnosis and overtreatment, the more people there are who believe they owe their health or even their lives' (Raffle; Gray, 2007, p. 68) to medical interventions, contributing to strengthening medicalization process.
Table 1 illustrates that the inclusion of moderate to low-risk increases NNT, amplifying harms due to reduced prospects of benefit, while expanding the market for 'preventive' medications. Take for example NICE guidelines (United Kingdom, 2014) for lipid disorders: if the person being assessed by QRISK ${ }^{\circledR}$ calculator has a $10 \%$ or greater risk of having a cardiovascular event, like one MI in ten years, clinicians are authorised to offer statin as a preventive measure. This group of people has been converted into a 'high-risk' group purely through population health modelling (Bauer, 2013) configuring an example of primary prevention, since they do not have clinically established CHD.

The proliferation of risk device predictors (i.e. clinical decision-support software, or web-based self-tests) within which individuals have to adjust themselves 'to routinized likelihoods, hedged bets and probable outcomes', have strengthened a speculative preventive model of practicing medicine (Adams; Murphy; Clarke, 2009, p. 247). Several electronic templates are employed to inform individuals of their future adverse outcomes. These include cardiovascular risk assessment (QRISK2 ${ }^{\circledR}$ template), the 10-year prediction of absolute fracture risk (FRAX2 template) or even the use of isolated biomarkers such as HbAic to predict micro-vascular complications. In the UK, general practice can use three different CVD risk-assessment scores (Framingham, Joint British Society 2 (JBS2), and QRISK $^{\circledR}$ 2). Nevertheless, the two first devices are known to overestimate the risk "by up to fifty per cent in most contemporary northern European populations, particularly for people living in more affluent areas and underestimate risk in higher risk populations, such as people who are the most socially deprived' (United Kingdom, 2013, p. 156). Thus, despite the aspiration of precise and individualised type of preventive medicine, reality shows otherwise, since these forecasting tools vary in their external validity (Bayer; Galea, 2015).

The prospect of extending a preventive individualised intervention to those with low to moderate risk has turned this type of preventive measure questionable, regardless of how the numbers are constructed to create sound 'evidence' (Abramson et al., 2013). In market economy, the high-risk 
strategy to disease prevention has been adopted, because it also produces 'certain economic profit, a certain political utility [...] supported by global mechanisms and, finally, by the entire system of the State' (Foucault, 2003, p. 33). In this context, the state has become the animator of the biomedical sector economy by strengthening the market of biomedical technologies and pharmaceutical industries (Rose, 2006).

\section{Final Remarks}

This article has critically analysed what Geoffrey Rose refers to as 'additive' preventive activities via high-risk strategy, i.e., the prescription of artificial substances (usually a drug) to an individual patient to prevent unwanted outcomes. Nevertheless, HRS can be safely used when reducing individual's exposure to potential health hazards, i.e. restoring body's 'normal' physiological condition as in the reduction of tobacco and excessive alcohol consumption, processed food intake and food pesticide usage, and sedentarism. These lifestyle measures 'can be presumed to be generally safe, and they can therefore be accepted on the basis of a reasonable presumption of benefit' (Rose, 1992, p. 94). They are also theoretically consistent and validated by the available evidence and scientific knowledge. However, we understand that policymakers should concentrate efforts in population risk/mortality burden intervention policies to improve health more generally rather than focusing on "the overestimations of the utility of individual risk factors in causing ill health in populations' (Starfield et al., 2008, p. 583).

Finally, awareness of sophisticated biases and vested interests in biomedical research is building momentum within the scientific community. The Choosing Wisely movement (Malhotra et al., 2015) and the recent "The Evidence-Based Medicine Manifesto for Better Healthcare" are setting an agenda for a real EBM that favours a more comprehensive and holistic view of clinician-patient relationship and reduction of 'questionable research practices, bias, and conflicts of interests' (Heneghan et al., 2017). By shedding light on the misapplication of HRS as a mainstream preventive approach to the masses we echo and reaffirm the same voices. The introduction of a technological fix via HRS to tackle the burden of disease in a population is a primary source of overdiagnosis, and consequently overtreatment, since most healthy people who are being labelled and treated will not succumb to the fateful outcome awaiting them. This medicalization process is morally and technically unjustified (Heath, 2010) and the public and health professionals need to be aware of the underlying issues which have led to this state of affairs.

\section{References}

ABRAMSON, J. D. et al. Should people at low risk of cardiovascular disease take a statin? British Medical Journal, London, v. 347, p. f6123, out. 2013.

ADAMS, V.; MURPHY, M.; CLARKE, A. E. Anticipation: technoscience, life, affect, temporality. Subjectivity, London, v. 28, n. 1, p. 246-265, 2009.

BAUER, S. Modelling population health: reflections on the performativity of epidemiological techniques in the age of genomics. Medical Anthropology Quarterly, Arlington, v. 27, n. 4, p. 510-530, 2013.

BAYER, R.; GALEA, S. Public health in the precision-medicine era. The New England Journal of Medicine, Waltham, v. 373, n. 6, p. 499-501, 2015.

COLLINS, C.; MCCARTNEY, G.; GARNHAM, L. Neoliberalism and health inequalities. In: SMITH, K. E.; BAMBRA, C.; HILL, S. E. (Ed.). Health inequalities: critical perspectives. Oxford: Oxford University Press, 2016. p. 124-137.

CURRIE, C. J. et al. Survival as a function of HbA1c in people with type 2 diabetes: a retrospective cohort study. The Lancet, London, v. 375, n. 9713 , p. 481-489, 2010.

DORAN, T. et al. Setting performance targets in pay for performance programmes: what can we learn from QOF? British Medical Journal, London, v. 348, p. g1595, mar. 2014.

FOUCAULT, M. Society must be defended: lectures at the Collège de France, 1975-76. New York: 
Picador, 2003. (Série Lectures at the Collège de France, 3).

GALLAGHER, J. Diabetes cases soar by $60 \%$ in past decade. $B B C$ News website, London, 17 ago. 2015. Disponível em: <http://bbc.in/1gOGDq8>. Acesso em 23 ago. 2017.

GREENHALGH, T.; HOWICK, J.; MASKREY, N. Evidence based medicine: a movement in crisis? British Medical Journal, London, v. 348, p. g3725, jun. 2014.

HARRISON, S. The politics of evidence-based medicine in the United Kingdom. Policy \& Politics, Bristol, v. 26, n. 1, p. 15-31, 1998.

HARRISON, S.; MORAN, M.; WOOD, B. Policy emergence and policy convergence: the case of "scientific-bureaucratic medicine" in the United States and United Kingdom. The British Journal of Politics and International Relations, London, v. 4, n. 1, p. 1-24, 2002.

HEATH, I. Person-centered prevention and health promotion. International Journal of Integrated Care, London, v. 10, n. 5, p. 92-93, 2010.

HEATH, I. The politics of fear. British Medical Journal, London, v. 342, p. d1273, mar. 2011.

HENEGHAN, C. et al. Evidence based medicine manifesto for better healthcare. British Medical Journal, London; v. 357, p. j2973, jun. 2017.

KELLY, M. P. et al. The importance of values in evidence-based medicine. BMC Medical Ethics, London, v. 16, n. 1, p. 69, 2015.

KONTOPANTELIS, E. et al. Investigating the relationship between quality of primary care and premature mortality in England: a spatial whole-population study. British Medical Journal, London, v. 35o, p. h904, mar. 2015.

LAMBERT, H. Accounting for EBM: notions of evidence in medicine. Social Science \& Medicine, Boston, v. 62, n. 11, p. 2633-2645, 2006.

LENZER, J. Majority of panelists on controversial new cholesterol guideline have current or recent ties to drug manufacturers. British Medical Journal, London, v. 347, p. f6989, nov. 2013.
LOCK, M.; NGUYEN, V-K. An anthropology of biomedicine. Oxford: Wiley-Blackwell, 2010. MALHOTRA, A. et al. Choosing Wisely in the UK: The Academy of Medical Royal Colleges' initiative to reduce the harms of too much medicine. British Medical Journal, London, v. 350, p. h2308, maio 2015.

MARMOT, M. The health gap: the challenge of an unequal world. London: Bloomsbury, 2015.

MONTORI, V. V.; ISLEY, W. L.; GUYATT, G. H. Waking up from the dream of preventing diabetes with drugs. British Medical Journal, London, v. 334, p. 882, abr. 2007.

NORMAN, A. H. The quality and outcomes framework as a biomedical technology: consequences for UK general practice. 2015. Tese (Doutorado em Antropologia) - Department of Anthropology, Durham University, Durham, 2015.

NORMAN, A. H.; RUSSELL, A. J.; MERLI, C. The quality and outcomes framework: body commodification in UK general practice. Social Science \& Medicine, Boston, v. 170, p. 77-86, dez. 2016.

PELL, J. P. et al. Smoke-free legislation and hospitalizations for acute coronary syndrome. The New England Journal of Medicine, Waltham, v. 359, p. 482-491, jul. 2008.

POPAY, J.; WHITEHEAD, M.; HUNTER, D. J. Injustice is killing people on a large scale - but what is to be done about it? Journal of Public Health, Oxford, v. 32, n. 2, p. 148-149, 2010.

RAFFLE, A. E.; GRAY, J. A. M. Screening evidence and practice. Oxford: Oxford University Press, 2007.

REMBOLD, C. M. Number needed to screen: development of a statistic for disease screening. British Medical Journal, London, v. 317, p. 307-312, ago. 1998.

ROSE, G. The strategy of preventive medicine. Oxford: Oxford University Press, 1992.

ROSE, G. Sick individuals and sick populations. International Journal of Epidemiology, Oxford, v. 30, n. 3, p. 427-432, 2001. 
ROSE, N. The politics of life itself: biomedicine, power, and subjectivity in the twenty-first century. Princeton, NJ: Princeton University Press, 2006.

SPENCE, D. Kill the QOF. British Medical Journal, London, v. 346, p. f1498, mar. 2013.

STARFIELD, B. et al. The concept of prevention: a good idea gone astray? Journal of Epidemiology \& Community Health, London, v. 62, n. 7, p. 580-583, 2008.

TESSER, C. D.; NORMAN, A. H. Differentiating clinical care from disease prevention: a prerequisite for practicing quaternary prevention. Cadernos de Saúde Pública, Rio de Janeiro, v. 32, n. 10, p. 1-14, 2016.

UNITED KINGDOM. British Medical Association. National Health Service Employers. National Health Service Commissioning Board. Quality and outcomes framework guidance for the GMS contract 2013/14. London: Department of Health, 2013.
UNITED KINGDOM. National Institute for Health and Clinical Excellence. Lipid modification: cardiovascular risk assessment and the modification of blood lipids for the primary and secondary prevention of cardiovascular disease. London: NICE, 2014.

WELCH, H. G.; FISHER, E. S. Income and cancer overdiagnosis - when too much care is harmful. The New England Journal of Medicine, Waltham, v. 376, n. 23, p. 2208-2209, 2017.

WHITEHEAD, A. N. Science and the modern world. New York: The Free Press, 1967.

WHO - WORLD HEALTH ORGANIZATION. Health 2020: a European policy framework and strategy for the 21st century. Copenhagen: WHO, 2013.

WILKINSON, R. G.; PICKETT, K. The spirit level: why equality is better for everyone. London: Penguin, 2010.

\section{Authors' contribution}

Norman composed the first version. Hunter and Russell made very important contributions to the first version, participating in the discussion. Norman and Hunter wrote the final version of the article, and Russel revised the manuscript. All the authors contributed with critical revisions of content.

Received: $11 / 27 / 2016$

Approved: 07/06/2017 